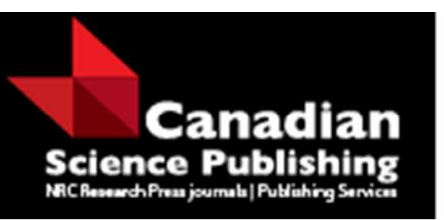

Canadian Journal of Physics Revue canadienne de physique

The thickness dependence of dielectric properties in the plasma polymer thin films

\begin{tabular}{|r|l|}
\hline Journal: & Canadian Journal of Physics \\
\hline Manuscript ID & cjp-2018-0138.R1 \\
\hline Manuscript Type: & Article \\
\hline Date Submitted by the Author: & 05-Mar-2018 \\
\hline Complete List of Authors: & Ulutas, Kemal; Istanbul Universitesi, \\
\hline $\begin{array}{r}\text { Keyword: } \\
\text { consideration in a Special } \\
\text { Issue? : }\end{array}$ & $\begin{array}{l}\text { dielectric properties, plasma polymerized poly(ethylene oxide), dielectric } \\
\text { loss, thin films, dielectric constant }\end{array}$ \\
\hline \multicolumn{2}{|c}{} \\
\hline
\end{tabular}

SCHOLARONE
Manuscripts 


\title{
The thickness dependence of dielectric properties in the plasma polymer thin films
}

\author{
Kemal Ulutaş \\ İstanbul University, Science Faculty, Physics Department Vezneciler, Istanbul, 34459 \\ TURKEY
}

\section{Abstract:}

In this study, the results of dielectric spectroscopy of plasma polymerized poly(ethylene oxide) thin films are presented. The films were deposited by plasma assisted physical vapour deposition at radio-frequency plasma discharge power of $5 \mathrm{~W}$. Thicknesses of the films have $20 \mathrm{~nm}, 100 \mathrm{~nm}, 250 \mathrm{~nm}$. Dielectric measurements of the films were performed in the frequency range of $10^{-1} \mathrm{~Hz}$ to $10^{7} \mathrm{~Hz}$ and temperature was scanned between $173 \mathrm{~K}$ and $353 \mathrm{~K}$. The dielectric constant $\left(\varepsilon^{\prime}\right)$ and dielectric loss $\left(\varepsilon^{\prime \prime}\right)$ of plasma polymerized poly(ethylene oxide) thin films were calculated by measuring capacitance $(C)$ and dielectric loss factor $(\tan \delta)$.

It was observed that there were two relaxation mechanisms in the investigated frequency range. These were called as $\alpha$ and $\beta$ relaxations. These relaxations shifts toward higher frequencies with incresing temperature. Besides, $\alpha$-relaxation starts to appear at different temperatures. This shows the difference between the polarizability abilities of samples at same temperature and same frequencies. The reason of this behavior can be expressed by dead layer concept which is a result of good adhesion of the bottom layer of plasma polymer to the substrate. By the light of these interpretations, with thinner samples it is possible to have structurally similar thin films like thin films deposited at high plasma power. A thinner film may support more transparent and these thinner films may be effective as coverage of optical devices such as lenses, visors etc. 


\section{Introduction}

Thermal, electrical and mechanical properties of polymers are useful for use in technological and biological applications [1-7]. Thin polymer films obtained by plasma polymerization are generally more biocompatible than conventional biomaterials such as Silastic. These films are suitable to change of the surface properties of the substrate without altering its bulk properties. Both the features together indicate the possible biomedical use of plasma polymerization as well as plasma treatment of polymer surfaces processes. Polyethylene oxide (PEO), a member of the polymer family, attracted much attention owing to its nonbiodegradable properties. Non-fouling properties were investigated by Choukourov et al. [8]. Non-fouling has many biomedical applications to limit or completely prevent the accumulation of proteins and microorganisms. Plasma poly(ethylene oxide) (pPEO) is used in biomedical applications, con- trolled drug delivery, packaging technologies and optical applications [9]. Plasma polymer thin films can be obtained at different methods as by changing the deposition pressure, deposition current, monomer flow rate and polymerization. They may have properties such as homogeneity, free from pinholes, water insolubility, high electrical resistance, chemical stability, high cross-linking density, good adhesion and thermal stability [7,10-13]. Plasma polymer thin films, were first deposited by Bradley and Hammes [14]. Furthermore, still it draws attention nowadays. [15-20]. In fact, It can be said that this method opens a new application area in material synthesis. There are various methods to examine the properties of materials such as structural, electrical, optical. Dielectric spectroscopy, one of these methods, is used to investigate the relationship between the structure and molecular dynamics of materials as polymers, plasma polymers and amorphous materials. There are studies in the literature that use dielectric spectroscopy to characterize the plasma polymer. $[12,13,21,22]$. In addition, there are reports on the dielectric properties of 
PEO, pPEO $[2,23,24]$ and on the comparison of their dielectric properties with the structural properties of plasma polymers [25- 29]. However, there are no reports on of the pPEO dependent on the film thicknesses.

In this work, pPEO thin film samples at different thickness $(20 \mathrm{~nm}, 100 \mathrm{~nm}, 250 \mathrm{~nm}, 500 \mathrm{~nm})$ was analyzed in the frequencies ranging between $10^{-2} \mathrm{~Hz}-10^{7} \mathrm{~Hz}$ and in the temperature ranging between $173 \mathrm{~K}$ and $433 \mathrm{~K}$. The dielectric constant $\left(\varepsilon^{\prime}\right)$ and dielectric loss $\left(\varepsilon^{\prime \prime}\right)$ of Plasma polymer thin films by plasma assisted physical vapour deposition at radio-frequency plasma discharge power of $5 \mathrm{~W}$ were calculated by measuring capacitance (C) and dielectric loss factor $(\tan \delta)$. In the given intervals, both the dielectric constant and the dielectric loss of the thin films decrease with increasing frequency, but increase with increasing temperature. This behavior can be explained as multicomponent polarization in the structure.

\section{Experimental}

Plasma polymer sample deposition was performed using a PAPVD system which was operated in a vacuum chamber with a base pressure of $10^{-3} \mathrm{~Pa}$ produced by rotary and diffusion pumps. A copper crucible with $4 \mathrm{~cm}$ deep was used for vaporization. One fourth of the crucible was filled with PEO granules (Sigma-Aldrich, Inc., Mn = $1500 \mathrm{~g} / \mathrm{mol}$ ) mixed with $\mathrm{Cu}$ granules for better heat transfer. The crucible was placed onto parallel molybdenum stripes in order to be heated to $340{ }^{\circ} \mathrm{C}$ and radio frequency (RF) magnetron with a graphite target, which was reduced the unwanted contribution of sputtered carbon, was placed $4 \mathrm{~cm}$ below the crucible to ignite a glow discharge. The experiments were performed in argon under $1 \mathrm{~Pa}$ pressure and $5 \mathrm{~cm}^{3} / \mathrm{min}$ flow rate and the discharge power was supplied with an RF generator (Dressler Ceasar-13,56 MHz). The samples were deposited with $5 \mathrm{~W}$ discharge power. A Quartz Crystal Microbalance (QCM) was used to adjust the deposition rate to 10 
$\mathrm{nm} / \mathrm{min}$. The thickness of the pPEO samples was measured by ellipsometry (Woollam M2000 DI). As the deposition conditions (Ar pressure and flow rate, the discharge power and deposition rate) were stabilized, the substrates were introduced into the chamber by a load lock. In order to have samples in a capacitor form, the top Al thin film electrodes were deposited onto the plasma polymer thin film samples. Thicknesses of the films have $20 \mathrm{~nm}, 100 \mathrm{~nm}, 250 \mathrm{~nm}$. The capacitance and dielectric loss factor of the plasma polymer thin film samples were measured using Alpha-N Impedance Analyzer (Novocontrol Inc.). The measurements were carried out in the frequency range between $10^{-1} \mathrm{~Hz}-10^{7} \mathrm{~Hz}$ and in the temperature range between $193 \mathrm{~K}-353 \mathrm{~K}$ with increments of $10 \mathrm{~K}$.

\section{Results and Discussion}

\subsection{Frequency and Temperature Dependence of Dielectric Constant ( $\left.\varepsilon^{\prime}\right)$}

Dielectric constant is derived from equation (1),

$\varepsilon^{\prime}=\frac{C d}{\varepsilon_{0} A}$

Where $\mathrm{C}$ is the capacitance of the sample, $\mathrm{d}$ is the thickness of the sample, $\varepsilon_{0}$ is the permittivity $[3,29,30]$

When the frequency dependent dielectric constant for the thin film with thickness of $20 \mathrm{~nm}$ was investigated, it was observed that there were two relaxation mechanisms. One of these mechanisms was observed at frequencies lower than $100 \mathrm{~Hz}$ and the other mechanism was observed at frequencies higher than $100 \mathrm{~Hz}$. The dielectric constant is 6 at room temperature at $100 \mathrm{kHz}$ as shown in Fig.1. 


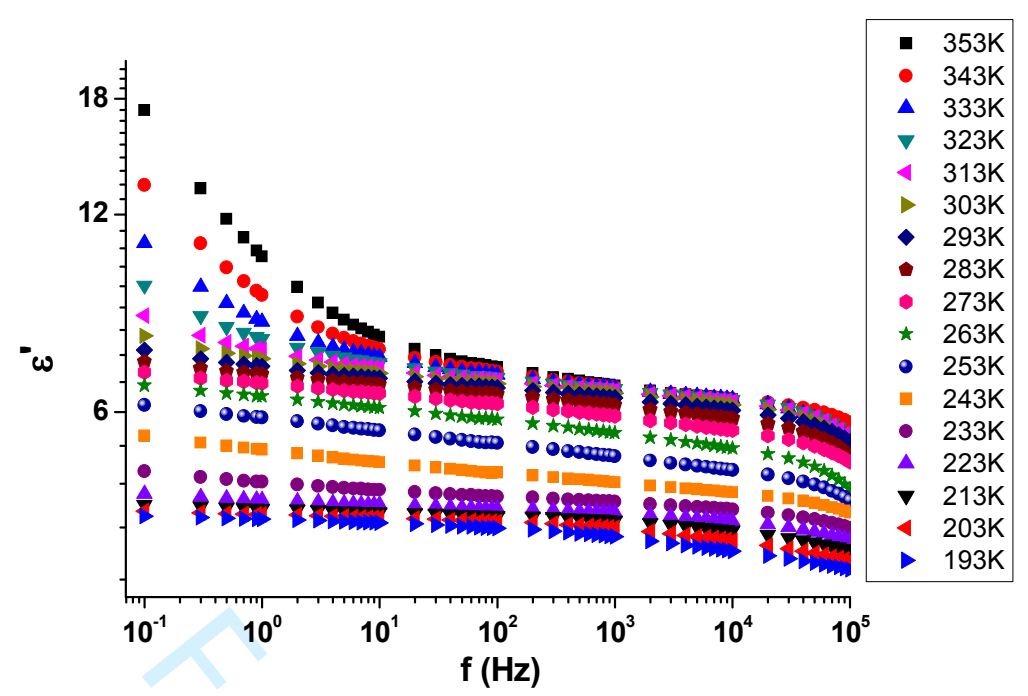

Fig. 1: Frequency and temperature dependence of dielectric constant for $20 \mathrm{~nm}$ thickness sample.

Similarly, two relaxation mechanisms are observed for 100, $250 \mathrm{~nm}$. However, the border between two relaxation mechanisms shifts toward higher frequencies from $100 \mathrm{~Hz}$. For 100 $\mathrm{nm}$ thickness sample the border is at $1 \mathrm{kHz}$ while it is at about $10 \mathrm{kHz}$ for $250 \mathrm{~nm}$ thickness sample. The dielectric constants are 13 and 14 from 100, $250 \mathrm{~nm}$ thickness samples as shown in Fig.2 and Fig.3. 


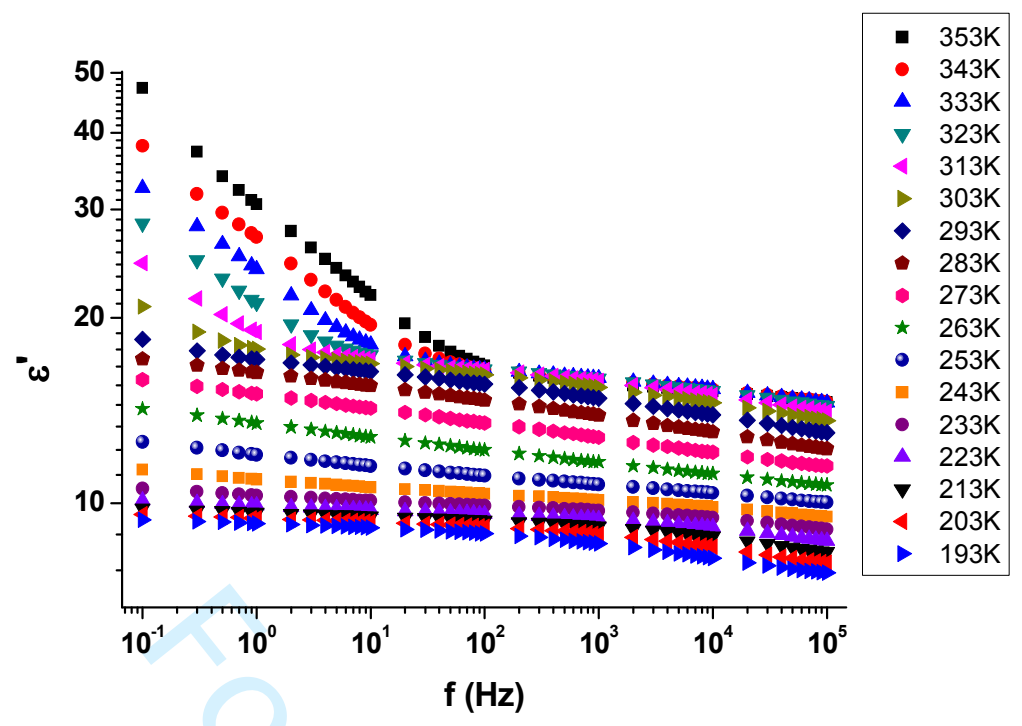

Fig. 2: Frequency and temperature dependence of dielectric constant for $100 \mathrm{~nm}$ thickness sample.

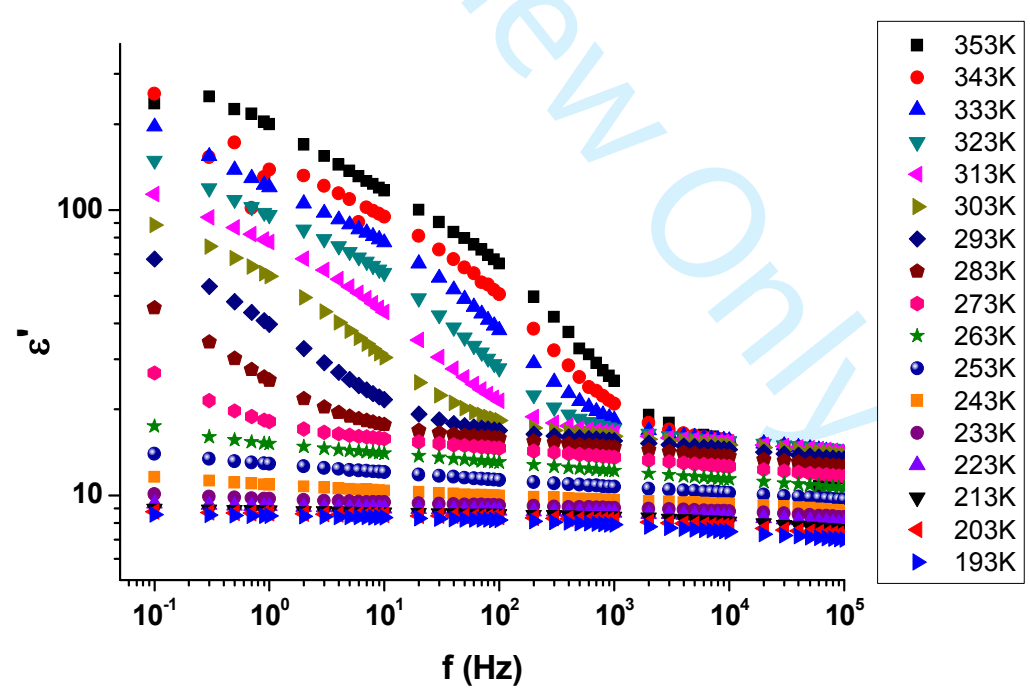

Fig.3: Frequency and temperature dependence of dielectric constant for $250 \mathrm{~nm}$ thickness sample. 
When the effect of temperature is investigated, it is observed that temperature has a rising effect on dielectric constant at all frequencies for all samples.

Sharp drops are detected for the mechanism observed at lower frequencies. This large reductions at dielectric constant may be the results of changing polarizability of large oligomer which are the large residues of PEO backbone as a result of plasma polymerization. The polarization of these large chain components are called as $\alpha$-relaxation $[31,32]$. This relaxation shifts toward lower frequencies with decreasing temperature. At higher frequencies at room temperature another mechanism is observed. It is think that this mechanism appears because of the polarization of free radicals originated from side chains and main chain of PEO and small oligomers. This mechanism is called as $\beta$-relaxation $[31,32]$. $\beta$-relaxation can be observed at lower frequencies by decreasing temperature.

\subsection{Frequency and Temperature Dependence of Dielectric Dissipation (tand)}

Dielectric dissipation is the ratio between dielectric loss and dielectric constant as shown in equation (2),

$$
\tan \delta=\frac{\varepsilon^{\prime \prime}}{\varepsilon^{\prime}}
$$

where $\varepsilon$ ' is dielectric loss which referres to the energy spent to interaction between polarized charges and the structure, $\varepsilon^{\prime}$ is dielectric constant which referres to the polarization of the charges in structure [33].

The presence of $\alpha$ and $\beta$ relaxation can be observed from frequency and temperature dependent $\tan \delta$. 
$\alpha$-relaxation can be observed only at temperatures higher than $293 \mathrm{~K}$ as shown in Fig.4. $\beta$ relaxation can be observed at lower temperatures as observed at frequency and temperature dependence of dielectric constant.

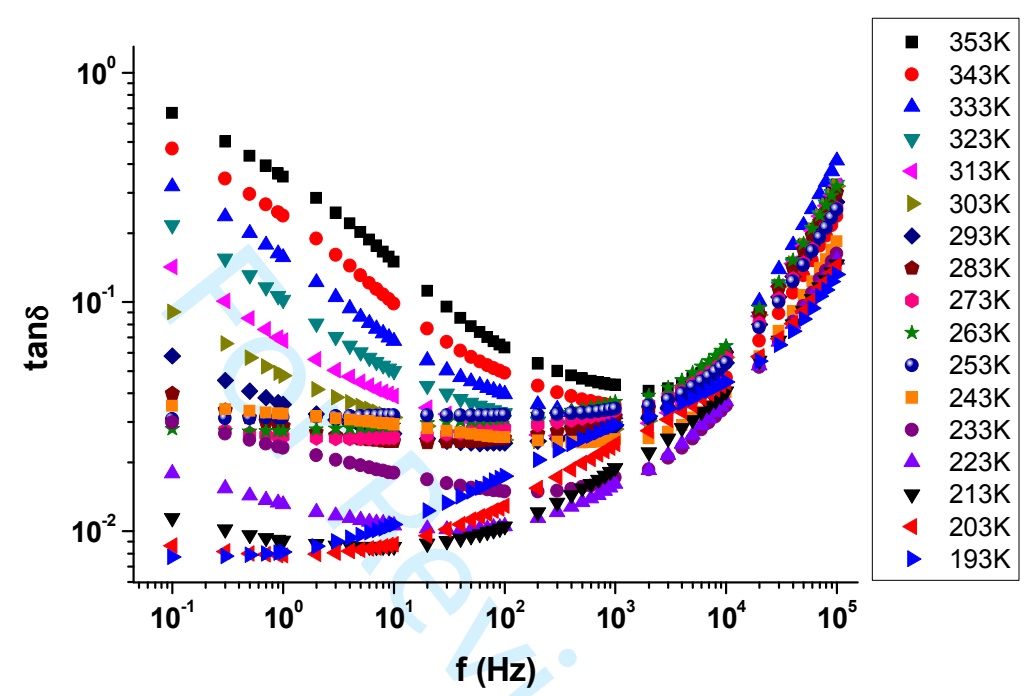

Fig.4: Frequency and temperature dependence of tan $\delta$ for $20 \mathrm{~nm}$ thickness sample.

The presence of $\alpha$-relaxation can be observed at temperatures higher than $283 \mathrm{~K}$ and $263 \mathrm{~K}$ for 100 and $250 \mathrm{~nm}$ thickness samples, respectively. 


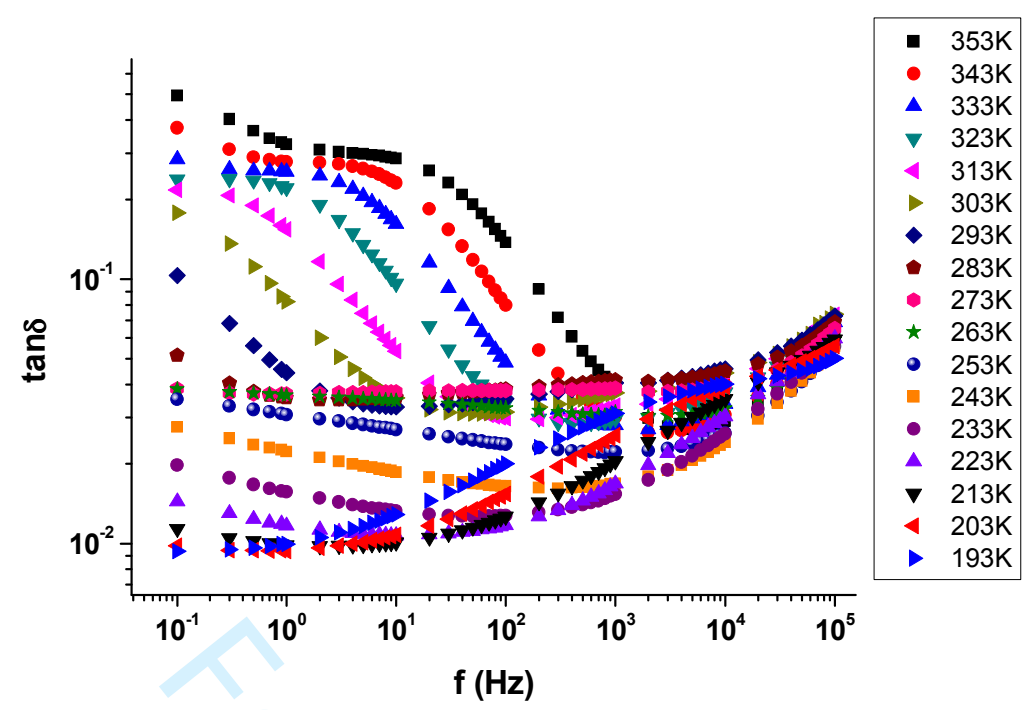

Fig. 5: Frequency and temperature dependence of tan $\delta$ for $100 \mathrm{~nm}$ thickness sample.

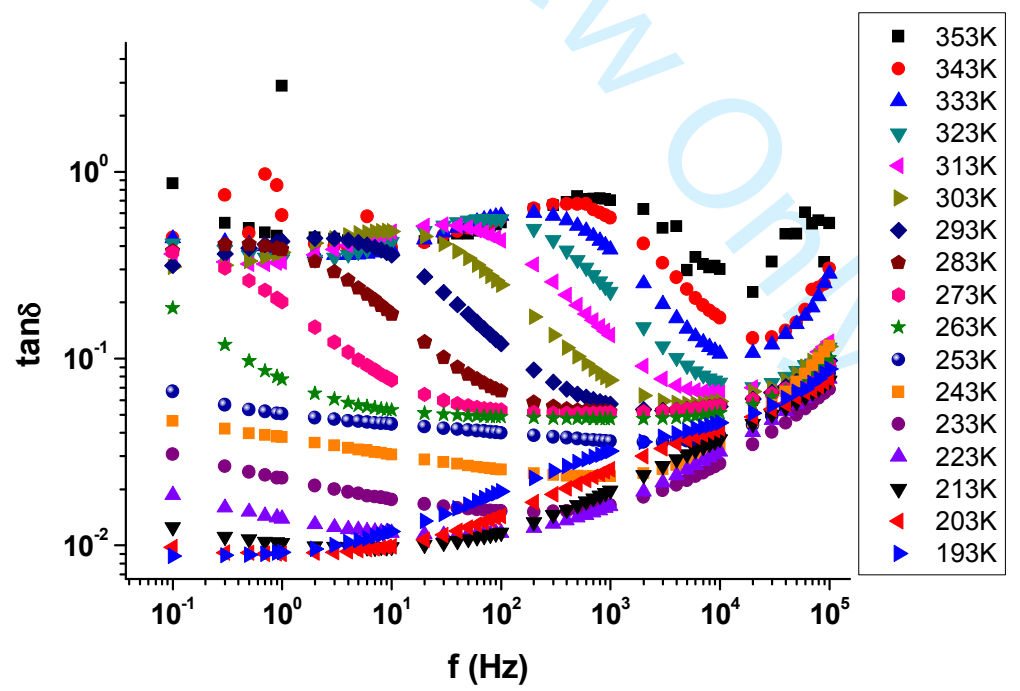

Fig. 6: Frequency and temperature dependence of tan $\delta$ for $250 \mathrm{~nm}$ thickness sample. 
The amplitudes of $\alpha$-relaxation are greater than of $\beta$-relaxation. This difference supports the interpretation indicating that the relaxation mechanism observed at lower frequencies, higher temperatures is $\alpha$-relaxation and the mechanism observed at higher frequencies, lower temperatures is $\beta$-relaxation $[34,35]$.

\subsection{Thickness Dependence of Dielectric Constant ( $\left.\varepsilon^{\prime}\right)$}

It is observed that dielectric constant decreases with decreasing thickness at room temperature as shown in Fig.5. Similar behavior can be observed for all temperatures.

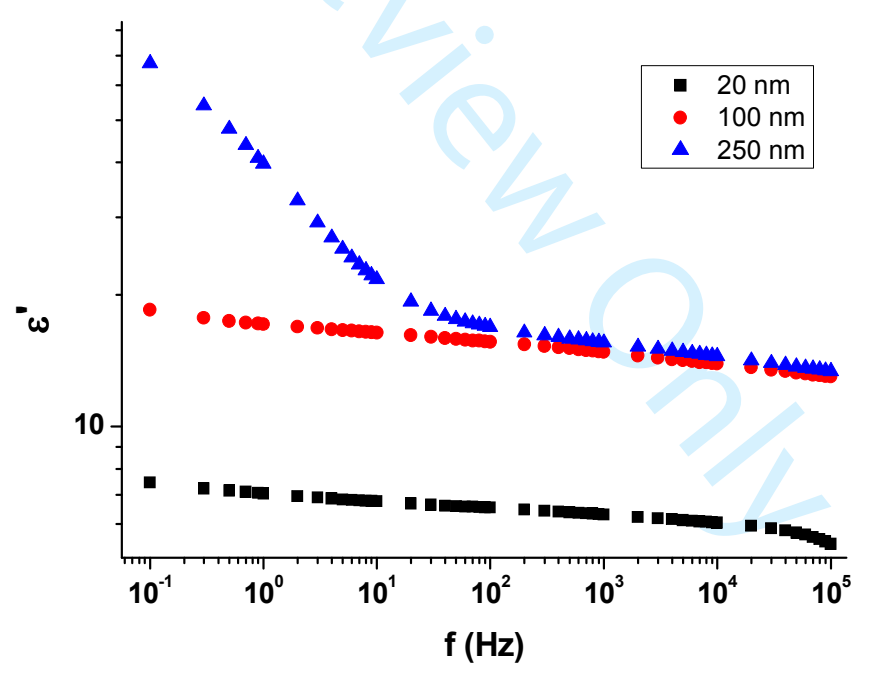

Fig.5: Thickness dependence of dielectric constant ( $\left.\varepsilon^{\prime}\right)$ at room temperature

When the thickness dependence of $\tan \delta$ is investigated, it is shown that the $\alpha$-relaxation shifts toward lower frequencies with decreasing thickness. Thus, $\alpha$-relaxation can not be detected at 
$20 \mathrm{~nm}$ in the investigated frequency range while it can be observed at $250 \mathrm{~nm}$ as shown in Fig.6.

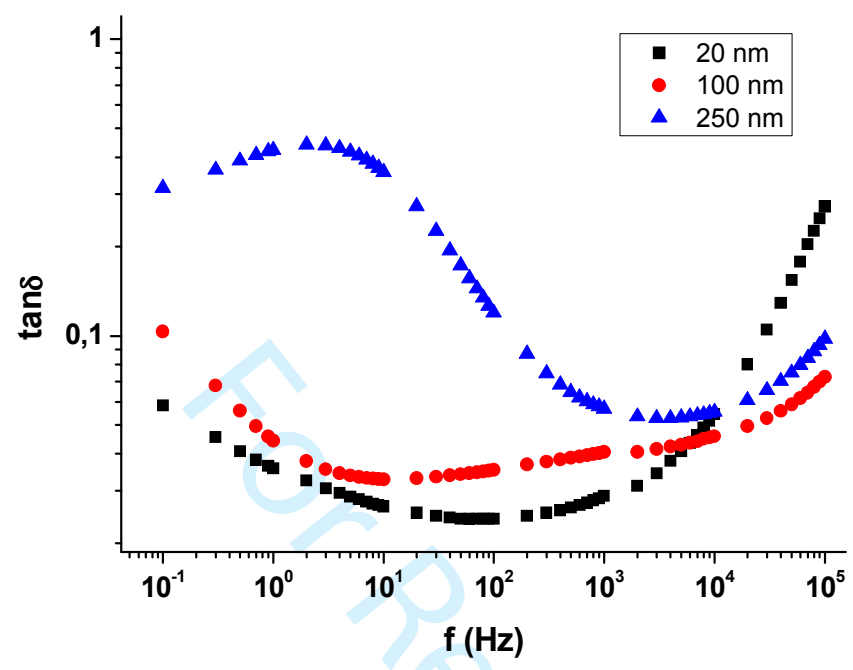

Fig. 6: Thickness dependence of dielectric loss factor (tand) at room temperature

Plasma polymers have the ability to hold to any substrates well due to the free radicals. This good adhesion ability is more difficult to adapt to the applied electric field change of these surfaces due to the good adhesion of the molecular groups on the surfaces of the plasma polymers that are in contact with the carrier surfaces compared to other molecular groups. These surfaces are called dead layers. Since the contribution of dead layer to total polarization will be more pronounced, the samples with low thickness will have lower polarization ability than thicker samples [36-39]. 


\section{Conclusion}

Plasma polymer thin film samples at different thicknesses were deposited at $5 \mathrm{~W}$ plasma discharge power. When the frequency, temperature and thickness dependence of dielectric constant and $\tan \delta$ were investigated, it was observed that there were two relaxation mechanisms in the investigated frequency range. These were called as $\alpha$ and $\beta$ relaxations. These relaxations shifts toward higher frequencies with increasing temperature. Besides, $\alpha-$ relaxation starts to appear at different temperatures. This shows the difference between the polarizability abilities of samples at same temperature and frequencies. The reason of this behavior can be expressed by dead layer concept which is a result of good adhesion of the bottom layer of plasma polymer to the substrate. When the investigations in this work were concerned, Plasma PEO thin films can be useful as coverage of optical devices such as lenses, visors etc. 


\section{References}

[1] S. Diaham, M.L. Locatelli, T. Lebey, S. Dinculescu, Dielectric measurements in large frequency and temperature ranges of an aromatic polymer, Eur. Phys. J. Appl. Phys. 49 (2010) 104011.

[2] E. Neagu, P. Pissis, L. Apekis, J.L.G. Ribelles, Dielectric relaxation spectroscopy of polyethylene terephthalate (PET) films, J. Phys. D. Appl. Phys. 30 (1997) 1551.

[3] N. Gondaliya, D.K. Kanchan, P. Sharma, M.S. Jayswal, M. Pant, Conductivity and dielectric behavior of AgCF3SO3 doped PEO polymer films, Integr. Ferroelectr. 119 (2010) 1.

[4] P. Saxena, M.S. Gaur, P. Shukla, P.K. Khare, Relaxation investigations in polysulfone: Thermally stimulated discharge current and dielectric spectroscopy, J. Electrost. 66 (2008) 584.

[5] A.A. Hashim (Ed.), In-The 2010, pp. 1-4 Vukovar, Croatia.

[6] S. Islam, G.V.S. Lakshmi, A.M. Siddiqui, M. Husain, M. Zulfequar, Synthesis, electrical conductivity, and dielectric behavior of polyaniline/V2O5 composites, Int. J. Polym. Sci. (2013) $1,307525$.

[7] S. Saravanan, C.J. Mathai, S. Venkatachalam, M.R. Anantharaman, Low k thin films based on RF plasma-polymerized aniline, New J. Phys. 6 (2004) 64.

[8] A. Choukourov, I. Gordeev, O. Polonskyi, A. Artemenko, L. Hanyková, I. Krakovský, et al., Polyethylene (ethylene oxide)-like plasma polymers produced by plasmaassisted vacuum evaporation, Plasma Process. Polym. 7 (2010) 445-458. 
[9] G.P. Löpez, B.D. Ratner, C.D. Tidwell, C.L. Haycox, R.J. Rapoza, T.A. Horbett, Glow discharge plasma deposition of tetraethylene glycol dimethyl ether for fouling-resistant biomaterial surfaces, J. Biomed. Mater. Res. 26 (1992) 415-439.

[10] E.E. Johnston, J.D. Bryers, B.D. Ratner, Plasma deposition and surface characterization of oligoglyme, dioxane, and crown ether nonfouling films, Langmuir 21 (2005) 870-881.

[11] K.E. Bremmell, P. Kingshott, Z. Ademovic, B. Winther-Jensen, H.J. Griesser, Colloid probe AFM investigation of interactions between fibrinogen and PEG-like plasma polymer surfaces, Langmuir 22 (2006) 313-318.

[12] B.W. Muir, A. Tarasova, T.R. Gengenbach, D.J. Menzies, L. Meagher, F. Rovere, et al., Characterization of low-fouling ethylene glycol containing plasma polymer films, Langmuir $24(2008) 3828-3835$.

[13] E. Sardella, R. Gristina, G.S. Senesi, R. D'Agostino, P. Favia, Homogeneous and micropatterned plasma-deposited PEO-like coatings for biomedical surfaces, Plasma Process. Polym. 1 (2004) 63-72.

[14] Z. Zhang, B. Menges, R.B. Timmons, W. Knoll, R. Förch, Surface plasmon resonance studies of protein binding on plasma polymerized di(ethylene glycol) monovinyl ether films, Langmuir 19 (2003) 4765-4770.

[15] A. Choukourov, A. Grinevich, O. Polonskyi, J. Hanus, J. Kousal, D. Slavinska, et al., Vacuum thermal degradation of poly(ethylene oxide), J. Phys. Chem. B 113 (2009) 29842989. 
[16] A. Choukourov, I. Gordeev, D. Arzhakov, A. Artemenko, J. Kousal, O. Kylián, et al., Does cross-link density of PEO-like plasma polymers influence their resistance to adsorption of fibrinogen? Plasma Process. Polym. 9 (2012) 48-58.

[17] K. Dušek, A. Choukourov, M. Dušková-Smrčková, H. Biederman, Constrained swelling of polymer networks: characterization of vapor-deposited cross-linked polymer thin films, Macromolecules 47 (2014) 4417-4427.

[18] A. Bradley, J.P. Hammes, Electrical properties of thin organic films, J. Electrochem. Soc. $110(1963) 15$.

[19] N.M. Bashara, C.T. Doty, Electrical conduction in very thin polybutadiene films formed in a glow discharge, J. Appl. Phys. 35 (1964) 3498.

[20] L.V. Gregor, Electrical conductivity of polydivinylbenzene films, Thin Solid Films 2 (1968) 235-246.

[21] X.Y. Zhao, M.Z. Wang, Z. Wang, Deposition of plasma-polymerized 1cyanoisoquinoline thin films and their dielectric properties, Plasma Process. Polym. 4 (2007) $840-846$.

[22] H. Jiang, L. Hong, N. Venkatasubramanian, J.T. Grant, K. Eyink, K. Wiacek, S. Fries Carr,J. Enlow, T.J. Bunning, The relationship between chemical structure and dielectric properties of plasma-enhanced chemical vapor deposited polymer thin films, Thin Solid Films 515 (2007) 3513-3520.

[23] A.V. Sarode, A.C. Kumbharkhane, Dielectric relaxation study of poly(ethylen 
[identification and molecular dynamics, Polymer 55 (2014) 6819-6826.

[24] D. Labahn, R. Mix, A. Schönhals, Dielectric relaxation of ultrathin films of supported polysulfone, Phys. Rev. E 79 (2009) 011801.

[25] A. Fahmy, R. Mix, A. Schönhals, J. Friedrich, Structure of plasma-deposited copolymer films prepared from acrylic acid and styrene: part II variation of the comonomer ratio, Plasma Process. Polym. 10 (2013) 750-760.

[26] A. Fahmy, R. Mix, A. Schönhals, J. Friedrich, Structure of plasma-deposited copolymer films prepared from acrylic acid and styrene: part I dependence on the duty cycle, Plasma Process. Polym. 9 (2012) 273-284.

[27] A. Fahmy, R. Mix, A. Schönhals, J. Friedrich, Structure-property relationship of thin plasma deposited poly(allyl alcohol) films, Plasma Chem. Plasma Process. 31

(2011) 477-498.

[28] A. Fahmy, R. Mix, A. Schönhals, J. Friedrich, Surface and bulk structure of thin spin coated and plasma-polymerized polystyrene films, Plasma Chem. Plasma Process.

32 (2012) 767-780.

[29] Mathai, C. J., Saravanan, S., Anantharaman, M. R., Venkitachalam, S., \& Jayalekshmi, S. (2002). Characterization of low dielectric constant polyaniline thin film synthesized by ac plasma polymerization technique. Journal of Physics D: Applied Physics, 35(3), 240. 
[30] Afroze, T., \& Bhuiyan, A. H. (2014). Alternating Current Electrical Properties of Thin Films of Plasma Polymerized 1, 1, 3, 3-Tetramethoxypropane. Advances in Polymer Technology, 33(2).

[31] Yakut, S., Ulutas, H. K., Melnichuk, I., Choukourov, A., Biederman, H., \& Deger, D. (2016). Dielectric properties of plasma polymerized poly (ethylene oxide) thin films. Thin Solid Films, 616, 279-286.

[32] Yakut, S., Ulutas, K., \& Deger, D. (2018). Plasma discharge power dependent AC conductivity of plasma poly (ethylene oxide) thin films. Thin Solid Films, 645, 269-277.

[33] Deger, D., Ulutaş, K., Yakut, Ş., \& Kara, H. (2015). Dielectric properties and ac conductivity of TlSbTe2 thin films. Materials Science in Semiconductor Processing, 38, 1-7.

[34] Chowdhury, F. U. Z., \& Bhuiyan, A. H. (2000). Dielectric properties of plasmapolymerized diphenyl thin films. Thin Solid Films, 370(1-2), 78-84.

[35] Karahaliou, P. K., Kerasidou, A. P., Georga, S. N., Psarras, G. C., Krontiras, C. A., \& Karger-Kocsis, J. (2014). Dielectric relaxations in polyoxymethylene and in related nanocomposites: identification and molecular dynamics. Polymer, 55(26), 6819-6826.

[36] Liang, T., Makita, Y., \& Kimura, S. (2001). Effect of film thickness on the electrical properties of polyimide thin films. Polymer, 42(11), 4867-4872.

[37] Napolitano, S., Prevosto, D., Lucchesi, M., Pingue, P., D'Acunto, M., \& Rolla, P. (2007). Influence of a reduced mobility layer on the structural relaxation dynamics of aluminum capped ultrathin films of poly (ethylene terephthalate). Langmuir, 23(4), 2103-2109.

[38] Keddie, J. L., Jones, R. A., \& Cory, R. A. (1994). Size-dependent depression of the glass transition temperature in polymer films. EPL (Europhysics Letters), 27(1), 59. 
[39] Wang, J., Kim, H. K., Shi, F. G., Zhao, B., \& Nieh, T. G. (2000). Thickness dependence of morphology and mechanical properties of on-wafer low-k PTFE dielectric films. Thin solid films, 377, 413-417. 